\title{
A arte sacra de Cláudio Pastro na Basílica Nacional de Aparecida: Um olhar contemporâneo sobre as imagens do Medievo
}

\author{
Richard Gomes da Silva \\ DOI 10.20396/eha.vil4.3443
}

Tendo passado quase um século desde a promoção do seu último concílio, a Igreja Católica, em meados do século XX, sentiu a necessidade de convocar novamente suas autoridades eclesiásticas para um novo sínodo, em busca de adaptar-se às condições dos novos tempos, a uma sociedade em constante transformação e às mudanças que passaram a ocorrer dentro do seio da própria religião.

No entanto, se durante o Concílio Ecumêncio Vaticano I (1869-1970), o foco era o debate acerca dos dogmas sobre o primado do Papa e da infalibilidade papal, o assunto principal, durante o Concílio Ecumêncio Vaticano II (1962-1965), era a modernização da Igreja que incluía, entre os diversos pontos apresentados, a necessidade de uma profunda reforma litúrgica.

Tal questão tornou-se uma das principais pautas do Concílio devido a uma série de discussões internas à Igreja sobre arte, teologia e liturgia, que passaram a ocorrer no início do século XX, trazendo à tona uma disseminação de iniciativas conhecida como Movimento Litúrgico, que buscava recuperar a importância do culto da Igreja cristã dos primeiros séculos, tomada pelo protagonismo das devoções particulares.

Pois se a religião cristã, que baseava-se fundamentalmente na celebração do culto eucarístico e na participação dos fiéis nele durante os primórdios do cristianismo, com o decorrer do tempo passou a relacionar-se mais efetivamente com as práticas de devoções privadas ${ }^{2}$ as quais trariam, por consequência, uma alteração significativa na relação dos fiéis com as imagens, principalmente a partir do século XIII, dado o surgimento das novas ordens mendicantes, de modo especial os dominicanos e franciscanos, que buscavam a conversão dos leigos através do uso as imagens devocionais

\footnotetext{
1 Mestre em História e Críttica da Arte - PPGartes UER]

2 No contexto da religião cristã, o termo devoção é compreendido como uma prática em que, partindo do subjetivo, o fiel constrói uma relação com o divino muito pessoal frente a religião. Segundo o Papa Pio XI, em sua Carta Encíclica Mediator Dei - Sobre a Sagrada Liturgia (...), "devoção" e que é o ato principal da virtude da religião com o qual os homens se ordenam retamente, se orientam oportunamente para Deus e livremente se consagram ao culto. (PIO XII, Papa. Carta Encíclica Mediator Dei-Sobre a Sagrada Liturgia. 1947, Item 29).
} 
em seus sermões ${ }^{3}$.

Assim, com o advento do Concílio Ecumênico Vaticano II, a Igreja propôs, então, uma reforma em todos os campos da liturgia, consolidando-a através de documentos conciliares como o decreto Perfectae Caritatis de 28 de outubro de $1965^{4}$, onde se lê:

A conveniente renovação da vida religiosa compreende não só um contínuo regresso às fontes de toda a vida cristã e à genuína inspiração dos Institutos, mas também a sua adaptação às novas condições dos tempos ${ }^{5}$.

Esse "regresso às fontes" teria sido, então, o tema principal da renovação litúrgica promovida pelo Concílio, que visava promover uma retomada da Igreja aos seguintes princípios:

Cristo voltando a tornar-se presença e centro de toda Igreja.

A liturgia (...) como conceito e realidade, o próprio Mistério Pascal do Cristo perpetuado na ação da Igreja. Os leigos cristãos (...) consciência de ser o povo de Deus, o Corpo de Cristo vivo no mundo. Liturgicamente, a assembleia cristã é convocada pelo próprio Cristo para celebrá-lo e quem preside é essa ação eclesial é o Cristo ${ }^{6}$.

E, é nesse contexto mistagógico que Cláudio Pastro, autodenominando-se artista pósconciliar, buscou ir ao encontro dos anseios dessa nova liturgia, desenvolvendo em sua obra uma linguagem simples e despojada, que pudesse ser capaz de promover o culto e, ao mesmo tempo, reaproximar o fiel do Mistério Pascal ${ }^{8}$.

Para isso, o artista recorreu às origens da arte cristã, e ao repertório do ícone de modo particular, para compor suas primeiras referências artísticas na concepção dos painéis azulejares do projeto de ambientação interna da Basílica Nacional de Aparecida (Figura 1).

Ao reportar-se à estética do ícone como ponto de partida de seu trabalho, Cláudio Pastro buscou refletir em suas representações, ainda que na forma de releituras, arquétipos dessa tipologia pictórica. Tais arquétipos são resultado do conjunto de normas para a arte sacra que integram a

\footnotetext{
3 QUÍRICO, T. Devoção por imagens: pinturas e culto privado na Itália, entre os séculos XIII e XV. Artigo acadêmico, 2015, pp. 79-80.

4 Os documentos do Concílio Vaticano II consistem em: 4 Constituições, 3 Declarações e 9 Decretos. Documentos do Concílio Vaticano II. Disponíveis em:<http://www.vatican.va/archive/hist_councils/ii_vatican_council/index_po.htm>. Acesso em: 29/11/2017.

5 PAULO VI, Papa. Decreto Perfectae Caritatis - Sobre a conveniente renovação da vida religiosa. 1965, Item 2.

6 PASTRO, C. Arte sacra. São Paulo: 2001, p. 13.

7 Termo grego que vem de myo e ago - conduzir - e etimologicamente significa a ação de introduzir uma pessoa no conhecimento de uma verdade oculta e no rito que a significa. O sacerdote, aquele que introduzia no mistério era chamado de mistagogo e a pessoa introduzida e iniciada era chamada de mystes. (PESENTI, G. G. 2003, p. 704 apud TOMMASO, W. de S. 2015, p.122-123).

8 O Mistério Pascal de Cristo, compreende a sua morte, Ressurreição e Clorificação, e está no centro da fé cristã, porque o desígnio salvífico de Deus se realizou uma vez por todas com a morte redentora do seu Filho, Jesus Cristo. (FINELON, Pe. V. G. Mistério Pascal. 2013).
} 
chamada "Santa Tradição", de origem oriental, transmitidas através dos tempos, pela qual a Igreja entende como sendo de fundamental importância.

Logo, tal como nas pinturas dos ícones, é possível observar, nos painéis azulejares da Basílica, uma bidimensionalidade abrangente, onde as figuras representadas recebem pouca atenção à anatomia, tendo seus corpos e suas vestes conformados através de uma série de contornos sóbrios, porém extremamente marcados, realçado pela regularidade e o ritmo dos azulejos dispostos sobre a superfície plana.

As figuras são desenhadas buscando-se, geralmente, uma postura bastante rígida, em um arranjo quase frontal das personagens onde, na maioria das vezes, rostos, pernas e pés são representados de perfil enquanto que, simultaneamente, olhos, ombros e troncos são vistos de frente criando assim, uma combinação simultânea de visão frontal e lateral da figura.

Esse complexo sistema de símbolos, códigos e normas do ícone medieval, pelos quais Cláudio Pastro buscou relacionar em sua obra, compreendeu também uma adequada disposição dos personagens nos retratos e nas cenas de grupos, a locação correta e hierarquizada de cada ícone nas cúpulas, absides e paredes das igrejas, além dos cenários arquitetônicos onde são inseridos os temas, personagens e etc.

Tal planejamento espacial encontra em Jérôme Baschet embasamento teórico oportuno que, ao tratar das imagens cristãs como imagens-objeto, configurou que elas assumem funções nos usos, nas manipulações e nos ritos - em sua maioria de caráter litúrgico.

Para esse fim, contudo, o medievalista acrescentou que essas imagens integram um conjunto mais amplo que engloba todos os elementos do edifício religioso, definindo esse espaço como lieu d'images (lugar de imagens): "um objeto, total, complexo, no qual as imagens se ligam entre si, se fundem com o lugar, e participam em sua função que é celebrar o culto de Deus e dos santos".

Segundo Baschet, "a disposição das cenas não [respondem] somente ao princípio de encadeamento narrativo: a posição de uma imagem [deve] também ser calculada de modo a se estabelecer uma relação significante com outras cenas".

Desse modo, tal como definido por Baschet, também as imagens na obra de Cláudio Pastro buscaram ocupar locais intrínsecos para o desenvolvimento de suas atribuições. Assim, o posicionamento dos ciclos narrativos azulejares de Pastro na Basílica de Aparecida, que compõe parte significativa do projeto de ambientação interna do espaço religioso, foi pensado também por esse viés.

Os ciclos narrativos azulejares são parte de todo o conjunto elaborado no projeto de ambientação erigida no interior do templo. Sendo 34 painéis divididos nas 4 naves da igreja de 


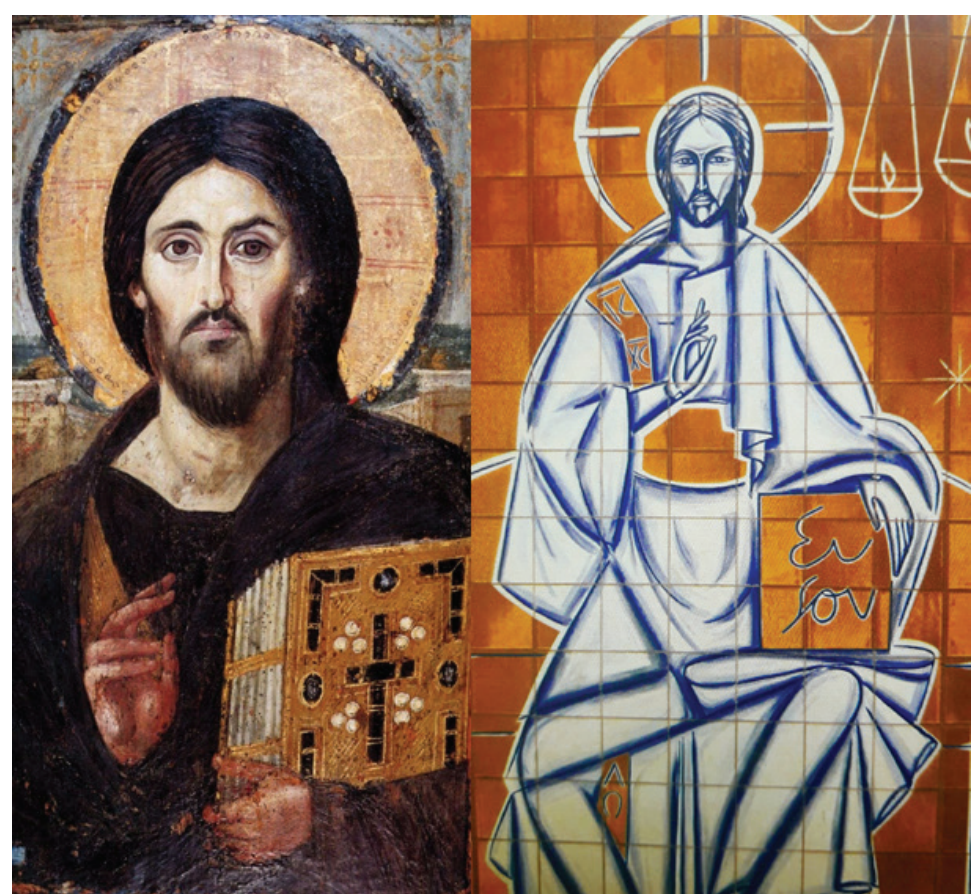

[Figura 1] À esquerda: Ícone do Cristo Pantocrator. Mosteiro de Santa Catarina, Monte Sinai, ca. sécs. VI-VII. À direita: Cláudio Pastro. Cristo Pantocrator. Basílica Nacional de Nossa Senhora Aparecida, São Paulo, ca. 2000-10.

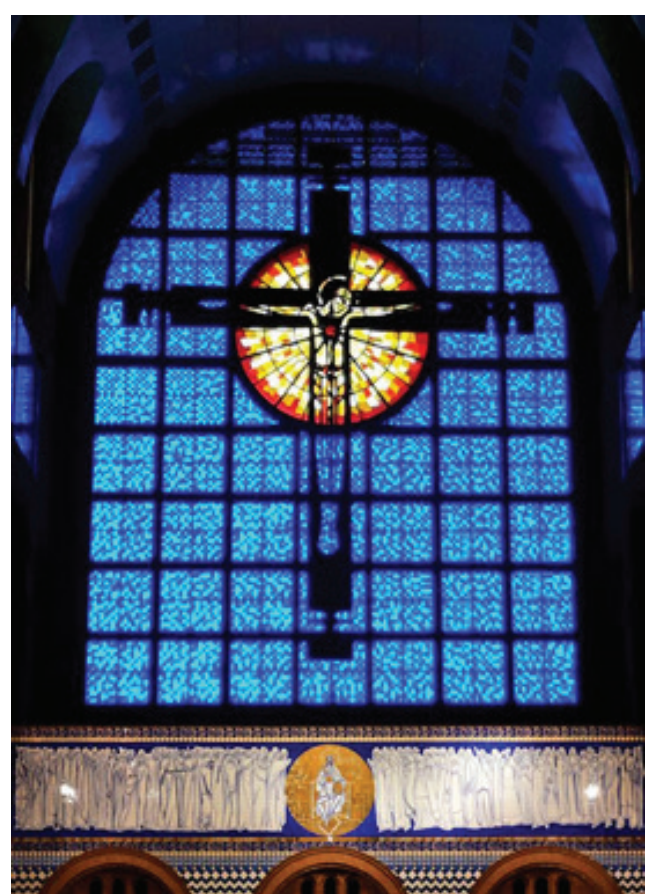

[Figura 3] Cláudio Pastro. Cruz do Nada localizada sobre o altar central da Basílica de Aparecida e, ao fundo, o vitral localizado acima do painel do Cristo Pantocrator na Nave Norte. Santuário Nacional de Aparecida, São Paulo, ca. 200-2017.

[Figura 2]

Localização dos ciclos narrativos azulejares no interior da Basílica de Aparecida, suas relações com o posicionamento solar e o sentido de interpretação de cada ciclo.

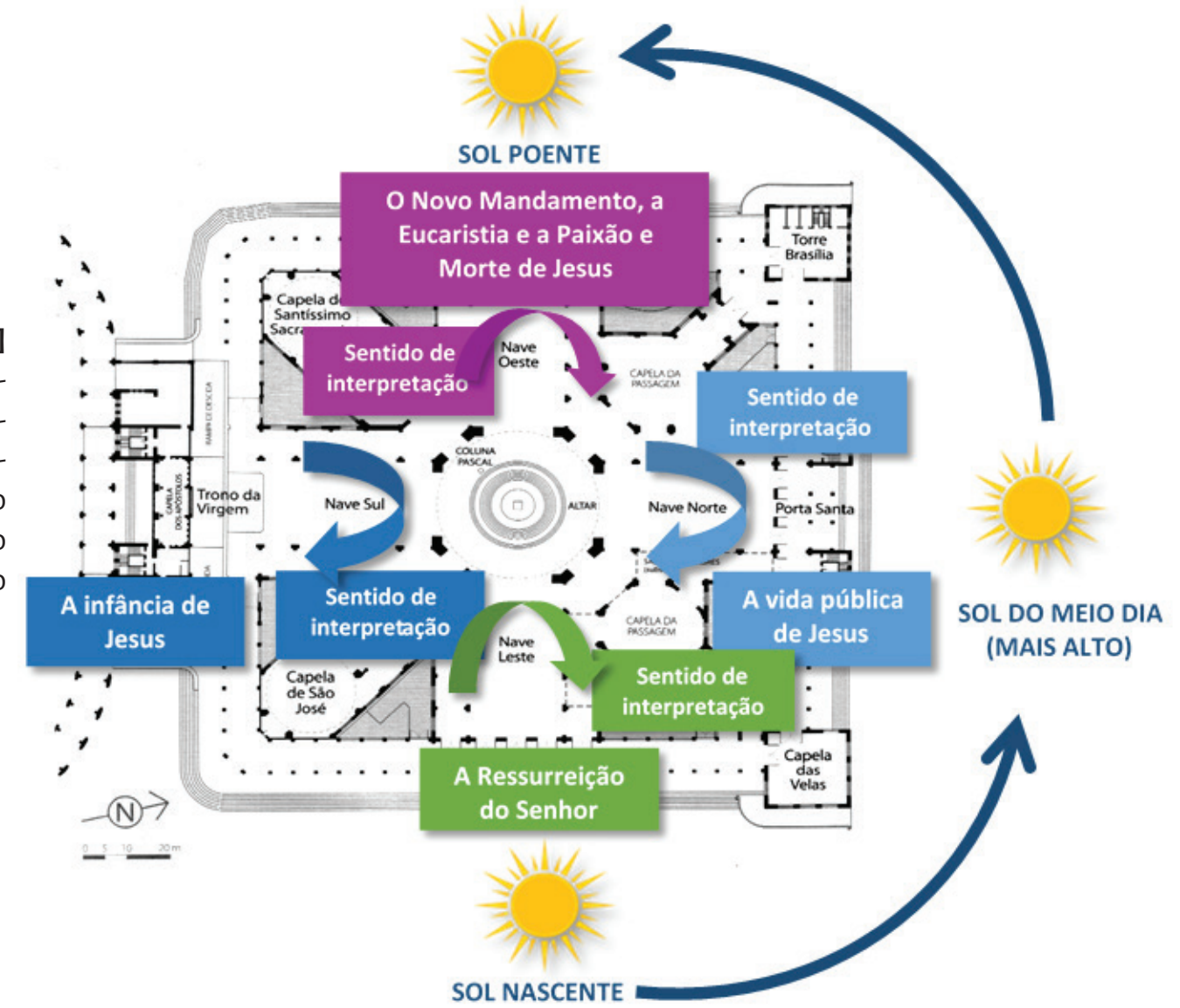


planta cruciforme, representando blocos de passagens do Nascimento, Vida, Morte e Ressurreição de Cristo.

Cláudio Pastro concebeu essas imagens como instrumento pedagógico das Escrituras, buscando distribuí-las em locais previamente calculados, de maneira que as mesmas pudessem cumprir seu papel no interior do espaço sagrado.

As cenas, tais como aquelas encontradas nas igrejas dos primeiros séculos, foram dispostas em arranjo simétrico de dimensões iguais, que constitui uma ideia de ordem entre os painéis do ciclo, e associadas diretamente ao posicionamento do sol, considerando as orientações cardeais das suas respectivas naves, construindo uma simbologia que reflete diretamente as passagens que estão sendo representadas (Figura 2).

Para essa distribuição, Cláudio Pastro retomou a definição do Concílio de Nicéia em 325, quando definiu-se que "a posição das igrejas fosse de tal modo que o maior número de fiéis orasse para o altar voltados para o sol (...), símbolo de Cristo que é sol da justiça e a luz do mundo"9

Como resultado, estabelecia-se a posição ad Orientem das igrejas, onde a abside e o altar eram colocados na extremidade leste do templo, de forma que os cristãos pudessem se voltar para o sol nascente que simbolizava o Cristo, enquanto o sol poente era entendido como uma metáfora do fim e da morte ${ }^{10}$.

De modo similar em Aparecida, Pastro distribuiu na Nave Leste da Basílica, voltados para a ala do sol nascente, 8 painéis azulejares. No entanto aqui, o nascimento do sol alude às passagens relacionadas à Ressurreição do Senhor. O sol, ao ressurgir diariamente, relembra ao fiel que o Cristo é aquele que ressuscitou dentre os mortos.

Na Nave Norte foram representados 8 episódios da Vida Pública de Jesus, sendo nessa orientação que o sol assume o ponto mais alto do dia no hemisfério sul. Desse modo, é nessa ala que Cláudio Pastro relacionou o sol com o próprio Cristo, ao distribuir as passagens do Novo Testamento que aludem ao pastoreio de Cristo, suas pregações, milagres e conversões, constituindo-se uma "luz para o mundo": "Falou-lhes, pois, Jesus outra vez, dizendo: Eu sou a luz do mundo; quem me segue não andará em trevas, mas terá a luz da vida"11.

Não é ao acaso também que o artista irá conceber para o painel acima da porta principal, localizada na Nave Norte, o painel do Cristo Sol (Pantocrator), uma imagem de Jesus onipotente tendo

\footnotetext{
9 GASPANI, A. 2000, p.25 apud QUÍRICO, T. Inferno e Paradiso: As representações do Juízo Final na pintura toscana do século XIV. Campinas, 2014, p. 148.

10 QUÍRICO, T. Inferno e Paradiso: As representações do Juízo Final na pintura toscana do século XIV. Campinas, 2014, p. 149.

11 João $8,12$.
} 
nas mãos o livro Sagrado cuja escritura ele autoproclama: "Eu Sou"12.

Na Nave Oeste, por sua vez, foram posicionados 8 painéis denominados Novo Mandamento, a Eucaristia, a Paixão e Morte de Jesus, cuja as passagens trazem os últimos momentos da vida de Cristo antes da sua crucificação.

Logo, sendo na orientação oeste o local onde o sol se põe ("morre"), Pastro retoma a metáfora da igreja dos primeiros séculos, que relacionava esta orientação com a morte de Jesus, que padeceu para que se cumprisse o seu destino de salvar a humanidade: "E, havendo-o açoitado, o matarão; e ao terceiro dia ressuscitará"13.

Entre as cenas deste conjunto destaca-se, também, a passagem da instituição da Eucaristia na Santa Ceia, centro do rito litúrgico e rememorada em todas as celebrações.

Já na Nave Sul, onde encontram-se distribuídas 10 passagens relativas à Infância de Jesus, Cláudio Pastro não buscou associar o conjunto ao posicionamento solar. Por outro lado, oportunamente, o artista procurou a relação entre essas cenas e o Trono de Nossa Senhora, um grande painel de pastilhas cerâmicas douradas que também se encontra na mesma ala, no qual destaca-se o nicho da Imaculada Conceição Aparecida, uma representação da Virgem de Nazaré grávida do Salvador.

O local, onde encontra-se a peça de terracota de aproximadamente $36 \mathrm{~cm}$ encontrada no século XVIII no Rio Paraíba, acaba por dialogar com os ciclos narrativos pois, justamente nesta ala, é onde a Virgem Maria irá figurar na maioria das cenas.

Os conjuntos das passagens da vida de Cristo também foram definidos por cores litúrgicas, seguindo os modelos do passado onde a disposição espacial das cenas, não só remetem aos acontecimentos contados no Novo Testamento como também se referem ao calendário litúrgico e suas cores.

No calendário litúrgico cada um dos tempos celebrados está associado a uma das cinco cores oficiais ${ }^{14}$. Essas cores são utilizadas durante as celebrações, nos paramentos dos clérigos e nas alfaias litúgicas, de acordo com o tempo vigente e derivam-se das cores tradicionais usadas pelos sacerdotes judeus no tempo de Cristo tendo, respectivamente, seus próprios sentidos simbólicos.

Entre elas, o azul é a cor do céu simbolizando, por isso, as realidades divinas e a santidade

\footnotetext{
12 A inscrição faz também referência ao evangelho de João, 8,12 onde Cristo diz: "Eu sou o caminho, e a verdade e a vida; ninguém vem ao Pai, senão por mim. E também quando Jesus diz: "Eu sou a porta; se alguém entrar por mim, salvar-se-á, e entrará, e sairá, e achará pastagens" (João 10,9). Nessa imagem, Cláudio Pastro buscou relacionar-se diretamente com a porta principal da Basílica por onde os fiéis entram.

13 Lucas, $18,33$.

14 Para melhor entendimento dos respectivos tempos litúrgicos, celebrados no calendário cristão, ver: A Instrução Geral do Missal Romano (3a edição). Congregação para o Culto Divino e a Disciplina dos Sacramentos. (Tradução portuguesa para o Brasil da separata da terceira edição típica preparada sob os cuidados da Congregação para o Culto Divino e a Disciplina dos Sacramentos). Roma, 2002, pp. 45-46.
} 
sendo tradicionalmente associada à Virgem Maria que é rainha do céu. E, embora não seja considerada uma cor oficial pela liturgia, a cor azul é comumente utilizada pela Igreja nas ocasiões especiais em locais que celebram as festas da Virgem Maria, como no caso de Aparecida.

Pastro se vale do tom azul real para retratar as passagens relacionadas à "Infância de Jesus" localizadas na Nave Sul dedicada à Virgem, assim como o artista também faz uso do tom azul cobalto nos painéis da "Vida Pública de Jesus", na Nave Norte, igualmente em uma alusão a figura de Maria que acompanhou seu filho durante toda a sua caminhada até Jerusalém, tendo sido personagem importante durante as Bodas de Canaã, quando Cristo realizou seu primeiro milagre, transformando água em vinho, a pedido de sua mãe, e que também compõe uma das cenas do conjunto.

Assim, o uso da cor azul no eixo norte-sul da Basílica marca uma clara linha visual que liga o Painel do Trono da Virgem de Aparecida ao Painel do Cristo Pantocrator, passando pelo altar no eixo da Basílica.

Cláudio Pastro fortalece essa conexão, posicionando um Cristo crucificado de de 8 metros em aço corten, pendendo sobre o altar, que ele denominou "Cruz do Nada" - em uma alusão ao vazio da figura que simboliza a entrega de Jesus no madeiro, tendo no peito o coração prenchido pelo ponto vermelho ${ }^{15}$ iluminado do vitral, localizado sobre o painel do Cristo Sol (Figura 3).

Tal imagem pode ser observada numa posição específica, localizada entre o painel de Nossa Senhora e o altar, voltando-se o olhar para a orientação Norte.

Segundo simbolismo de Pastro, a imagem da mãe Aparecida "volta-se" para o filho, representado tanto na cruz quanto no painel do Pantocrator, fazendo justamente alusão à fala da Virgem durante as bodas de Caná: "Fazei tudo o que ele vos disser"16.

Logo, a relação existente entre os ciclos narrativos azulejares, o seu posicionamento com a orientação solar, suas cores, assim como, o diálogo construído entre os paineis e os demais elementos no interior da Basílica tais como: o nicho da Virgem de Aparecida, a cruz e o vitral, foram pensados tomando como base o posicionamento que essas imagens ocupariam no templo.

Desse modo, tal como apontado por Jerôme Baschet, essas imagens, assim como as imagens medievais, também aderem a um lugar específico (lieu d'images - lugar de imagens) para que elas possam cumprir suas funções específicas enquanto imagem-objeto.

\footnotetext{
15 A cor vermelha é utilizada em detalhes dos painéis da Ressurreição de Cristo, nos vitrais do templo, assim como em outros elementos dos demais painéis da decoração interna da Basílica de Aparecida. Cláudio Pastro evitará, sobretudo, a cor preta nos painéis cerâmicos, preferindo, inclusive, adotar o azul nas linhas de construção das figuras representadas. 16 João 2,5 .
} 


\section{Referências bibliográficas}

A Instrução Geral do Missal Romano ( $3^{\mathrm{a}}$ edição). Congregação para o Culto Divino e a Disciplina dos Sacramentos. (Tradução portuguesa para o Brasil da separata da terceira edição típica preparada sob os cuidados da Congregação para o Culto Divino e a Disciplina dos Sacramentos). Roma, 2002.

BASCHET, Jérôme. A Civilização Feudal, do ano 1000 à colonização da América. São Paulo: Ed. Clobo, 2006.

Bíblia Sagrada. Tradução de Ivo Storniolo. Edição Pastoral. São Paulo: PAULUS, 1990.

FINELON, Pe. Vitor Gino. O Mistério Pascal. 2013. Disponível em: < http://arqrio.org/formacao/detalhes/173/o-misterio-pascal>. Acesso em: 15/01/2018.

PASTRO, Cláudio. Arte Sacra. São Paulo: Paulinas, 2001.

PAULO VI, Papa. Constituição Conciliar Sacrosantum Concilium - Sobre a Sagrada Liturgia. 1963. Disponível em: $<$ http://www.vatican.va/archive/hist_councils/ii_vatican_council/index_po.htm>. Acesso em: 29/11/2017.

PAULO VI, Papa. Decreto Perfectae Caritatis - Sobre a conveniente renovação da vida religiosa. 1965. Disponível em: $<$ http://www.vatican.va/archive/hist_councils/ii_vatican_council/index_po.htm>. Acesso em: 29/11/2017.

PIO XII, Papa. Carta Encíclica Mediator Dei - Sobre a Sagrada Liturgia. 1947. Disponível em: <http://www.vatican.va/ archive/hist_councils/ii_vatican_council/index_po.ht>. Acesso em: 29/11/2017.

QUÍRICO, Tamara. Inferno e Paradiso: As representações do Juízo Final na pintura toscana do século XIV. Campinas, São Paulo: Editora Unicamp, 2014.

QUÍRICO, Tamara. Devoções por imagens: pinturas e culto privado na Itália, entre os séculos XIII e XV. Artigo acadêmico, Antíteses, v.9, 2016.

SCHMITT, Jean Claude e GOFF, Le. Dicionário Temático do Ocidente-Tomo I. São Paulo: EDUSC, 2006.

SCHMMIT, Jean Claude. O corpo das imagens: ensaios sobre a cultura visual da Idade Média. São Paulo: EDUSC, 2007.

TOMMASO, Wilma Steagall de. Reflexões sobre o mistério na arte sacra. Artigo acadêmico, Teoliterária, v5, n.9, 2015. 